\title{
THE LEVELS OF FORMATION OF UKRAINIAN UNIVERSITY STUDENTS' PERSONAL SELF-DETERMINATION IN HIGHER EDUCATION \\ Masliuk K..$^{*}$, Koval V. ${ }^{2}$, Grygorenko T. ${ }^{3}$
}

${ }^{1 *}$ Candidate of Pedagogical Sciences, associate professor of the Chair of Ukrainian language with teaching methods, Pavlo Tyhyna Uman State Pedagogical University, Ukraine; ${ }^{2}$ Doctor of Pedagogical Sciences, Professor of the Chair of Ukrainian language with teaching methods, Pavlo Tyhyna Uman State Pedagogical University, Ukraine; ${ }^{3}$ Candidate of Philology, Associate Professor of the Chair of Ukrainian language with teaching methods, Pavlo Tychyna Uman State

Pedagogical University, Ukraine.

Email: "ua.education.com.ua@gmail.com

Article History: Received on $23^{\text {rd }}$ December 2019, Revised on $14^{\text {th }}$ April 2020, Published on $26^{\text {th }}$ May 2020

\begin{abstract}
Purpose: The article defines the levels of formation of the culture of personal self-determination of students of Ukrainian higher education institutions, namely, the formation of culture. This study uses the functional model to emphasize that self-determined behaviors must be defined within the context of the purpose or utility of such behavior for the student.
\end{abstract}

Methodology: Analyze the process of developing students' self-confidence in its social perspective on the basics of Ukrainian education using questionnaires, tests and surveys. The examination included 348 understudies from the control (178 people) and trial (170 people) gatherings and the confirmation phase of the analysis was held at three colleges.

Result: Diagnosis and analysis showed the reasons for the low and middle levels of the formation of the culture of personal self-determination of students because there is no clear definition in the content, forms and methods of work. In general, the distribution of students by the levels of effectiveness of life assignments will be illustrated.

Applications: This research can be used for the universities, teachers, and students. This qualitative study used a participatory action approach (focus group) to evaluate the perception of teachers, youth and parents of diverse ethnicities with regard to cultural influences on self-determination. Eight groups consisted of youth only, eight of parents only and four groups of teachers only.

Novelty/Originality: In this research, the model of the Ukrainian University Students' Self-Determination: Culture Formation Aspect is presented in a comprehensive and complete manner. Also, the main originality used in this study is in the case studies investigated. The cases were students who are the autonomous adolescences among all classified different age groups.

Keywords: Self-determination of Students, Formation of Culture, Diagnostics, Analysis, Reflection, Results.

\section{INTRODUCTION}

In humanistic pedagogy, there is a close connection between self-determination and the development of a person's culture. Self-determination is characterizes a person as a subject of his own life and happiness, advancing on one of the first places in the structure of the goals of education. At the same time, it is emphasized on the unlawfulness of delimiting the meaning of self-determination from the context of a person as a social being: a person lives for other people, for society, and society for a person. Self-determination can not be understood beyond the meaning of life, with it a tight sense of dignity, and a high level of self-consciousness (Bekh, 1991).

The problem of self-determination, the outline of its characteristic features attracts the attention of researchers of various branches of science. In the scientific sources, significant studies of the formation of the culture of personal selfdetermination of students are presented.

Particular attention is paid to the problem of self-determination in the period of youth when the ability to feel the state of others becomes heightened and emotionally tested. That is why youth "can be so sensational, so sophisticated in its manifestations in relation to other people ..." (orda, 2015).

For most young people, youth is correlated with student years. Students differ from other social groups by forms of organization of life, "localization" of lifestyle in institutions of higher educational, a student group. Educational process and related activities serve as a means of students' entry into an independent world, as well as a way of their selfrealization. The relative freedom of choice allows them to make their own decisions, bear responsibility for their actions.

At the same time, students have the following features of personal identification, as instability, lack of complete formation, lability, higher reaction to sociocultural situations. Modern students are characterized by a change in the traditional attitude towards themselves, which acquires the object character. The psychology of "victims", and "the consumer" spreads among the boys and girls. Unproductive types of behavior are formed, where the problems are solved by means of manipulation, strengthening of the exactingness to others with the simultaneous decrease in demanding to 
oneself (Viskovatova, 2013). All the mentioned complicates the process of personal self-determination in general and its culture in particular.

The theoretical basis of the research is quite broad, the studies were conducted by many scientists. Among them, it is necessary to highlight works written by Ilyazova M. D. (2008), Solodova G. G., and Prekina E. G. (2009), Kucherenko E.V. (2010), Laureano, R. M. et al, (2018), Dronenko V. H. (2010), Shirvani, M. et al, (2015), Metsämuuronen J. (2018), Villalobos, J. V. (2018), Malyhina H. S. (2013), Churpii K. L. (2013), Ajallooeian, E. et al, (2015), Solodova G. G., Galaganova L. E., and Epanchentseva, G. A. (2015) and others. This shows that the issues on which the article is oriented are quite relevant and widely demanded.

Orientation to the result (the desire to achieve the intended result, despite possible failures, difficulties, external barriers) is characteristic of $17.4 \%$ of experimental group students and $18.2 \%$ of control groups (mostly male). The focus on activity (domination of the value of practical activity) was recorded in $15.8 \%$ of experimental and $14.5 \%$ of control groups (gender differences were not recorded).

So in this exploration, rather than past examinations, the model of the Ukrainian University Students' SelfDetermination: Culture Formation Aspect is introduced in a far-reaching and complete way. Likewise, the principle inventiveness utilized in this examination is for the situation contemplates explored. Besides, the cases were understudies who are the independent adolescences among all characterized distinctive age gatherings.

\section{LITERATURE REVIEW}

Determination of the levels of formation of self-determination culture in the university students according to the emotional and value criterion was carried out on the basis of the author's questionnaire-test "Values of self-determination culture". A high level of awareness of the proposed values (the choice of the answer variant (2) turned out to be characteristic to $20.1 \%$ of experimental and $21.5 \%$ of control groups, incomplete or one-sided representation of the essence of cultural values - the average level (choice of option 3) was found in $46.3 \%$ of experimental and $44.8 \%$ of control groups. Other respondents (33.6\% of experimental group students and 33.7\% of the control group) showed false notions about the essence of values of freedom, responsibility, activity. Stukalova, O. V. (2017)

The results of the methodology "Diagnostics of the level of reflexivity development" allowed to distribute students by types and levels of development of reflexivity. It has been stated that students have a more situational and perspective reflection. The tendency to retrospective reflection was demonstrated by only $10.3 \%$ of experimental and $9.7 \%$ of control groups. Regarding the levels of reflexivity development, we obtained the following data: high reflexivity - $20.1 \%$ of experimental group students and $19.9 \%$ of the control group; the average level of reflexivity - $44.4 \%$ of experimental group students and $45.1 \%$ of the control group; a low level of reflexivity is in $35.0 \%$ of students. Zholdasbekova, S., Nurzhanbayeva, Z., Mavedov, R., Saipov, A., Zhiyentayeva, B., \& Tlemissova, A. (2016)

Consequently, only a relatively small number of students who participated in the qualitative stage of the experiment have an adequate level of development of reflexivity that was seen as a positive aspect for the formation of their selfdetermination culture in them. There are no clear differences in gender in the levels of reflexivity development. Although it is stated that perspective reflexivity is more characteristic of young men, while situational is of girls. Ezhov, S. G., Zaitseva, N. A., Smirnova, E. V., Khairullina, E. R., Kurikov, V. M., Nikonov, V. V., \& Gumerov, A. V. (2017)

The use of the methodology "Psychological culture of the individual" allowed to mention that according to the scale of the "strength of aspiration" students were distributed as follows: $19.7 \%$ of the respondents of the experimental and $20.6 \%$ of the control groups were at the highest level; at the pseudo-high level $-19.9 \%$ of the respondents of the experimental and $19.1 \%$ of the control groups; on the medium - 31.2\% of the respondents of the experimental and $31.9 \%$ of the control groups; on a low level $-28.2 \%$ of the respondents of the experimental and $28.4 \%$ of the control groups. Bunce, L., King, N., Saran, S., \& Talib, N. (2019)

As for the level of completeness of their implementation, the following results were obtained: the high level - $18.6 \%$ of experimental group students and $17.8 \%$ of the control group; pseudo-high level - 16,5\% of students of experimental and $16,8 \%$ of control groups; the medium level is $33.8 \%$ of experimental group students and $34.0 \%$ of the control group; low level $-31.4 \%$ of students.

Summarizing the results in both scales for each student allowed to determine the levels of harmony of the psychological culture: the high level - 19.5\% of the experimental group students and $19.2 \%$ of the control group; pseudo-high level $19,1 \%$ of experimental and $20,4 \%$ of control groups; the medium level is $34.6 \%$ of experimental group students and $35.8 \%$ of the control group; the low level $-26.8 \%$ of experimental group students and $24.6 \%$ of the control group.

It has been stated that high and pseudo-high levels of harmony of psychological culture are more characteristic of males, and the medium and low levels are of females. Kaplan, H., \& Madjar, N. (2017, August)

The generalization of the results by O. Potemkinova's methodology (diagnosis of socio-psychological instructors of the personality in the motivational area) has shown that the focus on the process (lack of awareness of the final result, the domination of interest in the content of the activity in conjunction with the negative attitude to the consistent 
implementation of the necessary actions) is characteristic to $18.7 \%$ of experimental group students and $17.7 \%$ of the control group (mostly females). Stupnisky, R. H., BrckaLorenz, A., Yuhas, B., \& Guay, F. (2018)

Freedom orientation (attitude to freedom as the highest value) was seen in $16.2 \%$ of experimental group students and $16.7 \%$ of the control group. Some correlation links with activity orientation have been recorded, although no significant gender differences have been identified.

According to the results of this methodology, students are divided into three groups according to the level of harmony of value orientations Johnson, M. L., Taasoobshirazi, G., Clark, L., Howell, L., \& Breen, M. (2016):

1. A group of highly motivated students with harmonious orientations: all orientations have the same high level of expression. This group consisted of $18.9 \%$ of experimental group students and $19.2 \%$ of the control group.

2. A group of low-motivated students, where all orientations are poorly expressed. This group included $45.4 \%$ of experimental group students and $46.5 \%$ of the control group.

3. A group with disharmonious orientations: some orientations are expressed excessively; others are not expressed at all. Such students were $35.7 \%$ of the experimental and $34.3 \%$ of the control groups.

Significant gender differences in this component technique were not detected.

According to "Methodology of life assignment" by O. Motkov, we found that more than half of respondents had clear orientations according to the following positions: Performer - $10.3 \%$ of students of experimental and $11.2 \%$ of control groups; Creator $-8.4 \%$ of students of experimental and $8.0 \%$ of control groups, Head $-12.5 \%$ of experimental and $11.9 \%$ of control groups, Subordinate - $16.8 \%$ of experimental and $17.2 \%$ of control groups, Self-Supporter $-10.8 \%$ of experimental and $9,7 \%$ of control groups, Supporter of others $-12.2 \%$ of students of experiments mental and $11.7 \%$ of control groups. In general, $71.0 \%$ of experimental group students and $69.7 \%$ of the control group were mentioned. Ju, S., Zeng, W., \& Landmark, L. J. (2017)

More acceptable to the formation of self-determination culture were the following positions: Creator, Head, Supporter of others. $19.0 \%$ of experimental group students and $19.2 \%$ of the control group had no clear orientation, and $10.0 \%$ of experimental and $9.8 \%$ of control groups were characterized by a combination of several positions.

Defining the level of severity of detected life orientations, it has been determined that $18.8 \%$ of experimental and $19.0 \%$ of control groups have a high level; the medium level is $44.5 \%$ of experimental group students and $45.9 \%$ of the control group; the low level is $36.7 \%$ of experimental group students and $35.1 \%$ of the control group. Sergis, S., Sampson, D. G., \& Pelliccione, L. (2018)

With regard to gender differences, it has been established that male representatives are more oriented towards the position of Head, Self Supporter, and Supporter of others. Female students prefer Performer, Creator, Subordinate positions, as well as the combination of several life assignments. Joo, Y. J., So, H. J., \& Kim, N. H. (2018)

The calculation of the level of effectiveness of life assignment has shown the existence of some differences between the level of their severity and the level of activity for their implementation. Thus, most activity is characteristic of the positions of the Head and Self-Supporter among male students, and among females, the Performer and Subordinate positions.

Based on the results obtained in the process of determining the initial level of formation of the self-determination culture of the university students according to the emotional and value criterion, the average arithmetic value is determined. The generalized level of formation of self-determination culture of the university students in the experimental group is (in $\%$ ): $\mathrm{H}_{\mathrm{e}}{ }^{0}=48,8 \%$; control $-\mathrm{H}_{\mathrm{c}}{ }^{0}=48.0 \%$ (difference in $0.8 \%$ ). These are mid-level indicators.

The results of the conducting methodology "Diagnosis of the acceptance of others" by V. Fey showed that $19.7 \%$ of experimental and $18.6 \%$ of control groups owned the high level of acceptance of others, i.e. the ability to make choices (60 or more points); the medium-level with a tendency to high (45-60 points) - 9.4\% of experimental group students and $9.0 \%$ of the control group; the medium level with a tendency to a low (30 - 45 points) - $40.3 \%$ of experimental group students and $43.1 \%$ of the control group; a low level (30 and less points) - 30.6\% of experimental group students and 29.3\% of the control group. Ilyazova M. D. (2008), Solodova G. G., and Prekina E. G. (2009), Kucherenko E.V. (2010), Laureano, R. M. et al, (2018), Dronenko V. H. (2010), Shirvani, M. et al, (2015)

Regarding the character of the response, it has been established that reactive reaction (lack of ability to control oneself) is characteristic of almost every fourth student, especially girls. Proactive response (the presence of a pause between stimulus and reaction to comprehend the choice of the best reaction, the ability to choose the way to respond to a particular situation, a sense of responsibility for it) is more characteristic of male students. Bekh, 1991)

\section{MATERIALS AND METHODS}

To analyze students' self-determination formation in its cultural aspect in Ukrainian institutions of higher education, we conducted the experiment. The verification stage of the experiment was held at three universities (Pavlo Tychyna Uman 
State Pedagogical University, Hryhoriy Skovoroda Pereyaslav-Khmelnytskyi State Pedagogical University, and Volodymyr Vynnychenko Kirovohrad State Pedagogical University). The experiment involved 348 students from the control (178 persons) and experimental (170 persons) groups.

The determination of the quantitative composition of the participants in the experiment was carried out on the basis of the table by M. Grabar and K. Krasnianska (Genisher, 2011), according to which the number of participants should not be less than 340 persons. The sample was carried out through the random choice of student groups. According to the Wilcoxon-Mann-Whitney empirical criterion, it is 0.39731 , and the critical value is 1.96 . It means that the characteristics of the comparative samples coincide at the level of significance of 0.05 . Consequently, the qualitative and quantitative composition of the students in the experimental and control group is approximately the same.

While analyzing and summarizing the results of students' tasks conducting (by questionnaires, tests, surveys), it is foreseen to identify possible differences between the levels of culture formation of the university student selfdetermination in terms of three criteria: cognitive, emotional and value, and regulatory and activity.

The generalization of the results of guided projection technique usage has shown that the vast majority of students do not have a clear idea of self-knowledge and self-esteem, and it is difficult for them to choose the ways of their defining. The distribution of students' results of this method was as follows: positive conscious self-attitude is recorded in 19.8\% of experimental group students and $20.3 \%$ of the control group; neutral attitude (sometimes due to lack of knowledge about oneself) $-42.7 \%$ of experimental group students and $43.5 \%$ of the control group; negative self-esteem - $37.6 \%$ of experimental group students and $36.2 \%$ of the control group. Some gender differences are stated: positive, supported by the knowledge of oneself, as well as negative self-attitude, which is more characteristic to males than females. Most girls found neutral attitude towards themselves, although some of them $(5.1 \%$ of the respondents of experimental and $4.7 \%$ of control groups) had a positive and negative (6.2\% of the respondents of experimental and $6.9 \%$ of control groups) selfattitude.

The willingness to change, to know oneself, to influence the formation and development of the personal qualities of the student as a whole (the test "Readiness for self-development" by V. Pavlov) were determined on two scales. According to the first scale ("I want to know myself"), the highest readiness for self-knowledge (7 points) was confirmed by $18.1 \%$ of experimental group students and $19.3 \%$ of the control group representatives. To find out the readiness on the scale "I can improve myself", the following results were obtained:

A. «I can improve myself», but «I do not want to know myself». This parameter comprised $22.6 \%$ of experimental group students and $23.0 \%$ of the control group.

B. "I want to know myself" and "I can change". 19.8\% of experimental group students and $19.0 \%$ of the control group were characterized according to this statement.

V. "I want to know myself," but "I can not change myself." The parameter is characteristic to $30.4 \%$ of experimental group students and $31.7 \%$ of the control group.

G. "I do not want to know myself" and "I do not want to improve myself" - $27.2 \%$ of experimental group students and $26.3 \%$ of the control group.

\section{RESULTS}

According to the cognitive criterion, the determination of the initial level of culture formation of the university students' self-determination was carried out based on the test "Do I know myself". The results showed that $19.6 \%$ students of the experimental and $18.6 \%$ student of the control group had in-depth knowledge of themselves; $44.1 \%$ of experimental group students and $45.8 \%$ of the control group had satisfactory knowledge; bad knowledge or their absence was found in $36.3 \%$ of experimental group students and $35.6 \%$ of the control group.

Male students showed better results according to the mentioned methodology (indicators of self-knowledge criterion in culture formation of the university students' self-determination). They mostly chose a positive answer to the questions asked, without facing any difficulties. This conclusion is also confirmed by the fact that only 25 girls from the total number involved in the verification stage of the experiment gave positive answers to the questions concerning yesterday's return, behavior in difficult situations, changes in behavior during the year, the choice of the case.

The analysis of the results obtained using a guided projection methodology showed that $74.5 \%$ of experimental group students and $75.1 \%$ of the control group identify themselves with persons similar to them. It is established that the correlation of oneself with the character "A" ("Self") is less conscious and projective, whereas the attitude towards the character "B" can be characterized as "Not-Self". The second task that students performed within the framework of this methodology and the results of its evaluation were conducted according to the categories "sympathy - antipathy", "respect - disrespect". Showing sympathy, respect for character "A", students emphasized such qualities as honesty, decency, sense of duty, responsibility, self-understanding, and self-acceptance.

Thus, the use of the "Readiness for self-development" test made it possible to conclude that the largest number of students of experimental and control groups who participated in the stage of the experiment did not believe in the 
possibility of self-change, neither self-knowledge or self-improvement. The most favourable in terms of the formation of self-determination culture was considered to be a B position. However, only $19.8 \%$ of experimental and $19.0 \%$ of control groups followed it.

Gender differences are recorded on the following parameters: boys, on the one hand, are keen to know themselves and recognize the possibility of self-change for the better, on the other hand, among them, there is a noticeable stratum (35.6\% of the respondents of the experimental and 36.2\% of the control groups), those who want to know themselves, but do not believe in the possibility of self-change. A noticeable number of girls do not want either to know or to improve themselves.

The generalization of the results by all scales of the test-questionnaire by V. Stolin and S. Pantelieyev is presented in the table. 1.

Table 1: Levels of student self-esteem by test-questionnaire by V. Stolin, S. Pantelieyev, \%

\begin{tabular}{|c|c|c|c|c|c|c|}
\hline \multirow[t]{3}{*}{ Scales } & \multicolumn{6}{|c|}{ Levels } \\
\hline & \multicolumn{2}{|c|}{ High } & \multicolumn{2}{|c|}{ Medium } & \multicolumn{2}{|c|}{ Low } \\
\hline & EG & CG & EG & CG & EG & CG \\
\hline Scale S (integral) & 19,0 & 19,2 & 47,7 & 46,4 & 33,3 & 34,4 \\
\hline Self-respect scale & 19,8 & 20,4 & 48,8 & 47,9 & 31,4 & 31,7 \\
\hline Scale of auto-sympathy & 17,7 & 18,1 & 51,8 & 52,8 & 30,5 & 29,1 \\
\hline Scale of expected attitude of others & 21,4 & 20,5 & 46,2 & 47,2 & 32,4 & 32,3 \\
\hline Scale of self-interest & 19,6 & 19,0 & 46,9 & 50,4 & 33,5 & 30,6 \\
\hline Scale of self-confidence & 25,2 & 24,7 & 42,0 & 41,8 & 32,8 & 33,5 \\
\hline Scale of attitude of others & 18,3 & 19,9 & 48,5 & 48,0 & 33,2 & 32,1 \\
\hline Scale of self-acceptance & 19,8 & 20,5 & 47,7 & 46,8 & 32,5 & 32,7 \\
\hline Scale of self-leadership & 16,7 & 15,3 & 47,7 & 48,2 & 35,6 & 36,5 \\
\hline Scale of self-excitation & 11,3 & 12,8 & 54,2 & 53,8 & 34,5 & 33,4 \\
\hline Scale of self-interest & 20,2 & 19,7 & 46,0 & 46,8 & 33,8 & 33,5 \\
\hline Scale of self-understanding & 19,7 & 20,5 & 45,9 & 45,0 & 34,4 & 34,5 \\
\hline
\end{tabular}

The generalization of the results on the scale of the control locus made it possible to state that the locus of I-control ("I am the owner of life") is characteristic of $17.5 \%$ of experimental and $15.9 \%$ of control groups (self-concept as a strong person with freedom of choice to build their lives in accordance with their own purposes and ideas about its meaning). $33.7 \%$ of experimental group students and $34.3 \%$ of the control group did not believe in their ability to control the events of their own lives, the conviction that human life is not subject to conscious control, the freedom of choice is illusory, so there is no sense to look into the future.

The data from Table 1 indicate that the largest number of students is at the medium level of self-esteem. The smallest number is seen at a high level of positive self-esteem on all scales. It is expected that more than a third of respondents have received low ratings for such important parameters for the formation of self-determination culture as self-esteem, self-interest, self-assertiveness, self-acceptance, self-management, and self-understanding. It has been stated that according to such scales as "self-confidence", "self-acceptance", "self-respect", "self-leadership", and "selfunderstanding", the majority of high points were scored by male representatives. Instead, females dominated in "expected attitude of others" and "self- excitation" scales.

Significant gender differences in the results of this method have not been recorded. In percentage terms, the distribution of students on the scale of the methodology "Diagnosis of self-actualization of personality" is presented in Table 2.

Table 2: Distribution of students by levels of ability to self-actualization, $\%$

\begin{tabular}{|c|c|c|c|c|c|c|}
\hline \multirow[t]{3}{*}{ Scales } & \multicolumn{6}{|c|}{ Level/amount } \\
\hline & \multicolumn{2}{|c|}{ High } & \multicolumn{2}{|c|}{ Medium } & \multicolumn{2}{|c|}{ Low } \\
\hline & EG & $\mathbf{C G}$ & EG & CG & EG & $\mathbf{C G}$ \\
\hline Scale of timing & 17,5 & 16,8 & 48,3 & 49,5 & 34,2 & 33,7 \\
\hline Scale of values & 19,1 & 19,5 & 45,7 & 43,7 & 35,2 & 36,8 \\
\hline Scale of a glance at the nature of man & 18,2 & 17,6 & 48,4 & 49,6 & 33,4 & 32,8 \\
\hline Scale of high need for cognition & 18,6 & 18,0 & 47,9 & 48,3 & 33,5 & 33,7 \\
\hline Scale of striving for creativity & 17,7 & 18,3 & 48,4 & 49,2 & 33,9 & 325 \\
\hline Scale of autonomy & 18,4 & 19,3 & 47,5 & 49,1 & 34,1 & 31,6 \\
\hline Scale of spontaneity & 18,6 & 17,4 & 47,6 & 45,2 & 33,8 & 37,4 \\
\hline Scale of self-understanding & 18,1 & 18,5 & 47,4 & 44,1 & 34,5 & 37,4 \\
\hline Scale of auto-sympathy & 19,3 & 20,5 & 47,2 & 48,5 & 33,5 & 31,0 \\
\hline Scale of contact & 19,8 & 18,6 & 46,6 & 47,2 & 33,6 & 34,2 \\
\hline Scale of communication flexibility & 19,8 & 21,3 & 46,8 & 48,0 & 33,4 & 30,7 \\
\hline
\end{tabular}


Gender differences are detected on some scales. Thus, according to the scale of the high need for cognition, male students had higher results, which is consistent with the results of the diagnosis of the formation of the selfdetermination culture of the university students on the indicators of the cognitive component. The advantage of males at a high level is also recorded on the scale of autonomy, self-understanding. Female dominated at a high level of ability to self-actualization on such scales as a striving for creativity, contact and flexibility in communication.

Data analysis in Table 3 proves that the average level of formation self-determination culture of the university students dominates at the stage of the ascertaining experiment (control group - $48.9 \%$ and experimental group - 49.5\%).

Table 3: Levels of the formed self-determination culture in the university students at the stage of the ascertaining experiment

\begin{tabular}{ccccc}
\hline \multirow{2}{*}{ Levels } & \multicolumn{2}{c}{$\begin{array}{c}\text { Experimental group } \\
\mathbf{1 7 0} \text { persons }\end{array}$} & \multicolumn{2}{c}{ Control group } \\
& 178 persons \\
\cline { 2 - 5 } & persons & \% & persons & \% \\
\hline High & 18 & 10,3 & 17 & 9,9 \\
\hline Medium & 84 & 49,5 & 88 & 48,9 \\
\hline Low & 68 & 40,2 & 73 & 41,3 \\
\hline
\end{tabular}

So, as the data of Table 3 shows most students who participated in the qualitative stage of the experiment have a medium level of formation self-determination culture. They had unsystematized knowledge about themselves, and ways to improve themselves, a general idea of cultural values (freedom, responsibility, activity), generally aware of the importance of their observance; sought to know themselves, their attitude to themselves and to cultural values (freedom, responsibility, activity) was unstable, could have a negative colour. These students were situationally focused on selfimprovement and active personal position; self-improvement and observance of cultural values (freedom, responsibility, activity) were sometimes referred to as pragmatism; they had a certain degree of ability to reflect, showed the ability to make choices, activity to achieve the goal, but needed external stimulation for this.

Based on the results obtained in the process of determining the initial level of formation of self-determination culture of the university students, a cognitive criterion was used to determine the arithmetic value, using the formula:

$$
H^{o}=\bar{x}=\frac{1}{n}\left(x_{1} n_{1}+x_{2} n_{2}+x_{3} n_{3}+x_{4} n_{4}+x_{5} n_{5}\right)
$$

where $\mathrm{H}^{0}$ is a generalized level of formation of self-determination culture in the university students.

$x$ is the average arithmetic mean.

$x_{i}$ is points.

$n_{i}$ is the corresponding repeatability of the indicators.

$n$ is the number of students in the group.

The results obtained in the process of determining the initial level of formation of self-determination culture in the university students according to the regulatory-activity criterion, allowed to establish the average arithmetic value. The generalized level of formation of self-determination culture of the university students in the experimental group is (in $\%$ ): $\mathrm{H}_{\mathrm{e}}{ }^{0}=49.8 \%$; control $-\mathrm{H}_{\mathrm{K}}{ }^{0}=50.0 \%$ (difference $0.8 \%$ ). These are mid-level indicators. The analysis of the results of the Pearson criterion calculation proves that according to the cognitive criterion it is $4.35,8.76$ for the emotional and value, and 0.82 for the regulatory and activity.

\section{DISCUSSION}

On the basis of the generalization of the results, the levels of formation self-determination culture of the university students had been defined - high, medium, and low. The results are shown in Table 3. A group of students, who have a low level of formation of the investigated personality education is characterized by fragmentary knowledge of oneself, unsystematized representations about cultural values (freedom, responsibility, activity). The students were not aware of the importance of their observance; they did not seek to know themselves, the attitude towards themselves and to cultural values (freedom, responsibility, activity). These students are not focused on self-improvement and active personal position; did not know how to improve themselves and to adhere to cultural values (freedom, responsibility, activity), lacked the ability to reflect, did not know how to make choices, to show activity to achieve the goal even in the presence of external stimulation.

Thus, the generalized level of formation of self-determination culture of the university students in the experimental group according to the cognitive criterion is equal (in \%): $\mathrm{H}_{\mathrm{e}}{ }^{0}=49.4 \%$; control $-\mathrm{H}_{\mathrm{c}}{ }^{0}=49.8 \%$ (difference $0.4 \%$ ). These are mid-level indicators. The generalization of the results obtained by this test made it possible to state that: the low scores for the subscale of the "life goals" are in $43.4 \%$ of the experimental and $42.9 \%$ of control groups, indicating their orientation to the present or the past. The other respondents had high scores, the interpretation of which (purposefulness 
or lack of a real basis, reinforcement of personal responsibility for their implementation) was carried out using indicators on other scales of sensual and life orientations.

Distribution under other parameters tests such indicators: increased need for success - $12.6 \%$ of experimental and $13.2 \%$ of control groups; the average need for success - $29.4 \%$ of experimental group students and $27.5 \%$ of the control group; the understated need for success $-9.1 \%$ of experimental group students and $9.5 \%$ of the control group. Besides, analysis of the results on the scale "process of life or interest and emotional richness of life" showed that $19.5 \%$ of experimental and $20.7 \%$ of control groups have a real interest in life, emotionally rich and full of meaning. $20.8 \%$ of experimental group students and $18.3 \%$ of the control group (high scores on this scale) belonged to hedonists living today. $59.7 \%$ of experimental group students and $61.0 \%$ of the control group reported low scores on this scale, viewed as a sign of their dissatisfaction with their lives. Nearly half of them (26.1\% of experimental group students and $25.8 \%$ of the control group) tried to improve their conditions by remembering the past (14.3\% of experimental group students and $16.7 \%$ of the control group) or hoping for a better future (11.8\% of experimental group students and $10.5 \%$ of the control group).

The most favourable for the formation of personal self-determination culture was the high and increased need for success, which was more characteristic of female students. The average expression of the need for success was found mainly in males. The gender gap in success has not been identified as a low or underestimated need.

Before introducing the "Test of sensual and life orientations" by D. Leontiev, a brief conversation was held. It was mentioned that the situation allows each person to make a choice in the form of act, action, or inactivity. The basis of this choice is the prevailing view of the meaning of life or its absence. The aggregate of the made actualized choices forms the "past", which is no longer possible to change; some variants can be subjected to only its interpretation. "Future" is a collection of potential, expected results from the efforts being made today. Therefore, the future is always open, and different variants of the expected future have a different value attraction.

The results of the use of test-affiliation have shown that the high level of development of the motive «striving for people» combined with the high level of development of the motive «concern to be ignored» is characteristic to $33.5 \%$ of experimental and $32.1 \%$ of control groups. The high level of development of the "striving for people" motive with a low level of development of the "fear to be ignored" motive is for $19.3 \%$ of experimental group students and $21.8 \%$ of the control group. The high level of development of the "fear of being ignored" motive combined with the low level of development of the motive "striving for people" is for $34.6 \%$ of experimental group students and $36.2 \%$ of the control group. The low level of development of both motives is characteristic for $30.7 \%$ of experimental group students and $29.3 \%$ of the control group. A relatively small number of respondents were in a more favorable situation regarding the formation of self-determination culture. Significant gender differences in the results of this method have not been identified.

The average arithmetic mean of the initial level of formation of self-determination culture of the university students in the experimental group is $49.4 \%$ for $K_{e}, 48.8 \%$ for $\mathrm{EV}_{\mathrm{e}}, 49.8 \%$ for $\mathrm{RA}_{\mathrm{e}}$ ); in the control group: $\mathrm{K}_{\mathrm{c}}-49.8 \%, \mathrm{EV}_{\mathrm{e}}-48.0 \%$, $\mathrm{RA}_{\mathrm{c}}-50.0 \%$ (EV - emotional and value criteria, RA - regulatory and activity criteria). These results point to the average starting level of the formation of self-determination culture in the university students. The analysis shows a slight difference in the indicators of the initial level of formation of the self-determination culture of the university students between the control and experimental groups separately for each criterion based on the results of the first assessment (a verifying experiment).

But even such a slight difference in the indicators of the initial level of the formation of self-determination culture in the university students between the control and experimental groups for each criterion requires verification of the validity of the results obtained using the Pearson criterion, which is calculated by the formula:

$\chi_{0}^{2}=\sum \frac{\left(n_{e}^{\prime}-n_{\kappa}^{\prime}\right)^{2}}{n_{\kappa}^{\prime}}$

Where $n_{e}^{\prime}$ is the experimental group indices

$n_{\kappa}^{\prime}$ is the control group indices.

Using Pearson's criterion means that if the values obtained are lower than the 9.49, then the difference between the levels of the formation of personal self-determination culture of the university students of the control and experimental groups is caused by accidental factors.

The scale of "life's result or satisfaction with self-realization" reflected the assessment of students' progress in terms of their fruitfulness and awareness. High scores (18.5\% of experimental group students and $19.0 \%$ of the control group) indicate focusing attention on the past, which at the same time makes sense to the present and future. Dissatisfied with the passing life of $24.4 \%$ of experimental and $23.6 \%$ of control groups, the remaining respondents ranked average on this 
scale. The generalization of the results on the scale of the control locus made it possible to state that the locus of Icontrol ("I am the owner of life") is characteristic of $17.5 \%$ of experimental and $15.9 \%$ of control groups (self-concept as a strong person with freedom of choice to build their lives in accordance with their own purposes and ideas about its meaning). $33.7 \%$ of experimental group students and $34.3 \%$ of the control group did not believe in their ability to control the events of their own lives, the conviction that human life is not subject to conscious control, the freedom of choice is illusory, so there is no sense to look into the future.

Consequently, a small difference in the digital values according to the levels of formation of self-determination culture of the university students of the control and experimental groups is due to random factors.

The smallest number of students showed a high level. They demonstrated a solid knowledge of themselves, their properties and ways of their improvement, clear representations of cultural values (freedom, responsibility, activity), aware of the importance of their observance; consciously sought to know themselves, characterized by a stable positive attitude towards themselves and to cultural values (freedom, responsibility, activity), focused on self-improvement and active personal position; they constantly developed themselves, adhered to cultural values (freedom, responsibility, activity), had a well-developed ability to reflect, skills to make choices, and showed activity in achieving the goal.

\section{CONCLUSION}

Summing up the results of the ascertaining stage of the experiment, we can conclude that:

1) Insufficient attention is paid to the formation of self-determination culture of the university students;

2) The relations between the participants in the pedagogical process are often marked by the subject-object orientation, negatively affecting the acquisition of students with the necessary knowledge, value orientations, and practical skills;

There is a lack of clearly defined content, forms, and methods of out-of-class work, ignoring the topics related to the formation of self-determination culture, inhibits the mastery of students with the necessary values and skills of their constructive manifestation.

\section{LIMITATIONS AND STUDY FORWARD}

One of the limitations of this research is the number of cases studied, both in terms of student nutrition and in terms of the number of universities surveyed.

\section{ACKNOWLEDGMENT}

The author confirms that the data do not contain any conflict of interest.

\section{REFERENCES}

1. Ajallooeian, E., Gorji, Y., \& Niknejadi, F. (2015). Evaluate the Effectiveness of Social Skills Training through Group Therapy Play on Reducing Rational Aggression Boy Elementary School Student in Esfahan City (2013-2014). Journal of Social Sciences and Humanities Research, 3(01), 1-5.

2. Bekh, I. D. (1991). Kontseptsiia vykhovannia osobystosti [The concept of education of the individual]. Radians' ka shkola, 5, 40-47.

3. Churpii, K. L. (2013). The role of teacher-curator in educational work with students. Medychna osvita Medical education, 1. 103-104.

4. Dronenko, V. H. (2010). Influence of educational activity on formation of the person in conditions of educational institution. Medychna osvita-Medical education, 1, 89-92.

5. Genisher, E.S. (2011). Pedagogical conditions of education of the student's legal culture. Vestnik OGU, 11 (130). 183-189.

6. Ilyazova, M. D. (2008). Competence-based approach and the tasks of development of a modern higher school. Siberian Pedagogical Journal, no 3. 61-78.

7. Korda, M. M. (2015). Ways of Implementation of the Law of Ukraine on Higher Education at the Ternopil State Medical University. Medychna osvita, 2. 34-38.

8. Kucherenko, E.V. (2010). Development of professional self-definition in future psychologists: integration and activity approach.

9. Laureano, R. M., Fernandes, A. L., Hassamo, S., \& Alturas, B. (2018). Facebook satisfaction and its impacts on fundraising: a case study at a Portuguese non-profit organization. Journal of Information Systems Engineering \& Management, 3(1), 04. https://doi.org/10.20897/jisem.201804

10. Malyhina, H. S. (2013). Responsibility of the person as a general psychological problem. Visnyk OPU. Psykholohiia. Vol.18, issue 4 (30).196-201.

11. Metsämuuronen, J. (2018). Common Framework for Mathematics-Discussions of Possibilities to Develop a Set of General Standards for Assessing Proficiency in Mathematics. International Electronic Journal of Mathematics Education, 13(2), 13-39. https://doi.org/10.12973/iejme/2693

12. Sakhnevych, I. D. (2014). Problems of comprehensive harmonious education of student youth. Visnyk Zhytomyrskoho derzhavnoho universytetu imeni Ivana Franka. 78. 
13. Shirvani, M., Mohammadi, A., \& Shirvani, F. (2015). Comparative study of cultural and social factors affecting urban and rural women's Burnout in Shahrekord Township. JOURNAL OF MANAGEMENT AND ACCOUNTING STUDIES, 3(01), 1-4.

14. Solodova, G. G., \& Prekina, E. G. (2009). Self-determination of personality as a necessary factor in the professional development of a modern teacher. Siberian Pedagogical Journal, (5), 131-140.

15. Solodova, G. G., Galaganova, L. E., \& Epanchentseva, G. A. (2015). Formation of professional selfdetermination of university students in the pedagogical culture of a changing society. Bulletin of the Kemerovo State University, (2-3 (62)), 104-111.

16. Villalobos, J. V. (2018). Politics as a requirement. On the concept of Human Rights and the right to an autobiography as an ethical category. Opción, 34(85-2), 9-19.

17. Viskovatova, T.P. (2013). Modern approaches to the problem of regulation of mental states of the individual. Visnik OPU.Vol. 18, issue 4(30). 55-59.

18. Ivchenko, N. O. (2013). Self-determination in the educational space. Pedagogichna majsternja - Pedagogical Workshop, 5 (29). Retrieved from http://journal.osnova.com.ua

19. Giuliano, E. (2015). The social bases of support for self-determination in East Ukraine. Ethnopolitics, 14(5), 513-522. https://doi.org/10.1080/17449057.2015.1051813

20. Spivakovska, E., Osipova, N., Vinnik, M., \& Tarasich, Y. (2014, June). Information competence of university students in Ukraine: development status and prospects. In International Conference on Information and Communication Technologies in Education, Research, and Industrial Applications (pp. 194-216). Springer, Cham. https://doi.org/10.1007/978-3-319-13206-8_10

21. Stukalova, O. V. (2017). The system of cultural and creative development of students in the educational environment of higher education institutions in the sphere of culture and art. Espasios, 38(56), 33.

22. Ezhov, S. G., Zaitseva, N. A., Smirnova, E. V., Khairullina, E. R., Kurikov, V. M., Nikonov, V. V., \& Gumerov, A. V. (2017). Pedagogical correction of university student professional self-alienation. https://doi.org/10.12973/ejac.2017.00282a

23. Zholdasbekova, S., Nurzhanbayeva, Z., Mavedov, R., Saipov, A., Zhiyentayeva, B., \& Tlemissova, A. (2016). Didactic conditions of improvement of pedagogical personnel training at higher education institutions to dual education in the system of VET. International Journal of Environmental and Science Education, 11(18), 12345-12359.

24. Kaplan, H., \& Madjar, N. (2017, August). The motivational outcomes of psychological need support among Pre-service teachers: Multicultural and self-determination theory perspectives. In Frontiers in Education (Vol. 2, p. 42). Frontiers. https://doi.org/10.3389/feduc.2017.00042

25. Bunce, L., King, N., Saran, S., \& Talib, N. (2019). Experiences of black and minority ethnic (BME) students in higher education: applying self-determination theory to understand the BME attainment gap. Studies in Higher Education, 1-14. https://doi.org/10.1080/03075079.2019.1643305

26. Stupnisky, R. H., BrckaLorenz, A., Yuhas, B., \& Guay, F. (2018). Faculty members' motivation for teaching and best practices: Testing a model based on self-determination theory across institution types. Contemporary Educational Psychology, 53, 15-26. https://doi.org/10.1016/j.cedpsych.2018.01.004

27. Johnson, M. L., Taasoobshirazi, G., Clark, L., Howell, L., \& Breen, M. (2016). Motivations of traditional and nontraditional college students: From self-determination and attributions, to expectancy and values. The Journal of Continuing Higher Education, 64(1), 3-15. https://doi.org/10.1080/07377363.2016.1132880

28. Ju, S., Zeng, W., \& Landmark, L. J. (2017). Self-determination and academic success of students with disabilities in postsecondary education: A review. Journal of Disability Policy Studies, 28(3), 180-189. https://doi.org/10.1177/1044207317739402

29. Sergis, S., Sampson, D. G., \& Pelliccione, L. (2018). Investigating the impact of Flipped Classroom on students' learning experiences: A Self-Determination Theory approach. Computers in Human Behavior, 78, 368-378. https://doi.org/10.1016/j.chb.2017.08.011

30. Joo, Y. J., So, H. J., \& Kim, N. H. (2018). Examination of relationships among students' self-determination, technology acceptance, satisfaction, and continuance intention to use K-MOOCs. Computers \& Education, 122, 260-272. https://doi.org/10.1016/j.compedu.2018.01.003 